УДК 624.131.37:624.131.43

ДЕФОРМАЦИОННЫЕ ХАРАКТЕРИСТИКИ ОТТАИВАЮЩИХ ГРУНТОВ ЕСТЕСТВЕННОГО СЛОЖЕНИЯ

Вахрин И.С., Кузьмин Г.П., Спектр В.В.

ФГБУН Институт мерзлотоведения им. П.И. Мельникова СО РАН, e-mail:VakhLIG2010@yandex.ru,kuzmin@mpi.ysn.ru,vvspector@mpi.ysn.ru

\begin{abstract}
Деформация оттаивающих грунтов обусловлена уменьшением их пористости вследствие отжатия воды и воздуха из пор грунта под действием собственной массы и приложенной внешней нагрузки. Чем больше пористость мерзлого грунта, тем больше величина его осадки при оттаивании. Причем это не зависит от того, в какой степени заполнены поры грунта льдом и незамерзшей водой. Влияние влажности (льдистости) на деформацию мёрзлого грунта при оттаивании неоднозначно. При изменении влажности мёрзлых грунтов в диапазоне от 0 до полной влагоёмкости деформационные характеристики остаются постоянными. При повышении влажности за пределом полной влагоёмкости коэффициенты оттаивания и сжимаемости, характеризующие величину осадки мёрзлых грунтов при оттаивании, возрастают. Эти положения были подтверждены результатами испытаний на компрессионном приборе искусственно приготовленных образцов. В данной статье излагаются результаты определения деформационных характеристик естественных грунтов ненарушенного сложения, образцы которых были отобраны при выполнении инженерно-геологических изысканий на строительных площадках в разных районах территории Якутии. Грунты различного состава, криогенного строения и генезиса, места отбора проб исследованных грунтов показаны на схематической карте Якутии. Приведены физические характеристики этих грунтов. Представлены в графическом виде коэффициенты оттаивания и сжимаемости почти трёхсот образцов различных типов грунтов естественного сложения и для сравнения образцов искусственного изготовления. Показано, что графики зависимости деформационных характеристик естественных грунтов ненарушенного сложения и искусственных образцов идентичны. Коэффициенты оттаивания и сжимаемости естественных грунтов с одинаковой пористостью при изменении влажности в диапазоне от 0 до полной влагоёмкости постоянны, а при увеличении влажности за пределом полной влагоёмкости они возрастают. Зависимости деформационных коэффициентов оттаивающих грунтов естественного сложения от пористости выражаются, как и коэффициенты искусственных образцов, линейной функцией и могут быть рекомендованы в качестве паспорта деформационных характеристик мёрзлых грунтов при оттаивании. Полученные результаты подтверждают, что величины деформационных характеристик мёрзлых грунтов при оттаивании определяются пористостью их и не зависят от степени заполнения пор льдом и незамерзшей водой. Небольшие ледяные тела выступают в данном случае как пористость. Поэтому расчёты осадки мёрзлых грунтов при оттаивании можно выполнять по данным определений коэффициентов оттаивания и сжимаемости без учёта криогенного их строения.
\end{abstract}

Ключевые слова: деформационные характеристики, компрессионые испытания, мёрзлый грунт, влажность, полная влагоёмкость, пористость

\title{
THAW DEFORMATION CHARACTERISTICS OF UNDISTURBED SOILS
}

\author{
Vakhrin I.S., Kuzmin G.P., Spektr V.V. \\ Melnikov Permafrost Institute SB RAS, Yakutsk, e-mail:VakhLIG2010@yandex.ru, \\ kuzmin@mpi.ysn.ru,vvspector@mpi.ysn.ru
}

Deformation of thawing soils is caused by the decrease in porosity due to drainage of pore water and air under their own weight and applied loads. The higher the porosity of a frozen soil, the greater its settlement upon thawing. This relationship is independent of the degree of saturation with ice and unfrozen water. The effect of water content (ice content) on thaw deformation is not straightforward. At water contents of frozen soils between 0 and full saturation, the thaw strain characteristics remain constant. When water contents increase above saturation, the coefficients of thawing and compressibility which characterize the amount of thaw settlement increase. These patterns were confirmed by thaw consolidation tests performed earlier on artificially prepared specimens. In this article, we present the results of tests that have been made on undisturbed samples collected in different areas of Yakutia during engineering site investigations. The tested soils vary in composition, cryostructure and genesis. Sampling sites are shown on the schematic map of Yakutia. The physical properties of test soils are described. The coefficients of thawing and compressibility are presented in graphical form for about 300 undisturbed samples, as well as for artificially prepared specimens for comparison. The thaw-strain plots for the undisturbed cores are shown to be identical to those for the artificial specimens. The coefficient of thawing and the coefficient of compressibility of the natural soils of the same porosity are constant over the range of moisture content from 0 to full saturation and increase with increasing moisture content above saturation. Similar to the artificial specimens, the relationships between the thaw-deformation coefficients and porosity of the undisturbed soils are described by a linear function and can be recommended as a reference for the thaw-deformation characteristics of frozen soils. The study results confirm that the thaw-deformation coefficients are dependent on porosity and independent of the degree of pore saturation with ice and unfrozen water. In this case, small ice bodies act as porosity. Therefore, coefficients of thawing and compressibility determined with no account for cryostructure can be used in thaw settlement analyses.

Keywords: deformation characteristics, consolidation tests, frozen soil, water content, saturated water content, porosity

Основной особенностью мёрзлых грунтов при оттаивании как деформируемого тела является наличие в них пор, объём которых под действием собственной массы и приложенной внешне нагрузки уменьшается. Образовавшаяся при таянии льда вода, незамёрзшая вода и воздух под действием нагрузки вытесняются из пор грунта. Дефор- 
мации мёрзлых грунтов принято характеризовать коэффициентами оттаивания и сжимаемости соответственно при отсутствии и наличии компрессионного давления $[1,2]$. Как видно из результатов компрессионных испытаний искусственных образцов, эти коэффициенты одинаково зависят от физических характеристик грунтов [3]. В диапазоне изменения влажности мёрзлых грунтов от 0 до полной влагоёмкости величина их не изменяется. При дальнейшем повышении влажности увеличивается пористость грунта вследствие раздвижения частиц грунта при промерзании и величины деформационных коэффициентов возрастают.

Целью исследования является выявление возможных особенностей деформирования оттаивающих естественных грунтов ненарушенного сложения и составления базы данных, проведены компрессион- ные испытания в условиях невозможности бокового расширения образцов грунта различного состава, строения и генезиса, отобранных при выполнении инженерногеологических изысканий на строительных площадках на территории Якутии.

\section{Материалы и методы исследования}

Объектом настоящих исследований являются мёрзлые дисперсные грунты естественного сложения, отобранные в процесce проведения инженерно-геологических изысканий на территории Якутии (рис. 1). Места отбора проб обозначены:

- № 1 - о. Котельный;

- № 2 - Амуро-Якутская железная дорога;

- № 3 - Трубопроводная система Восточная Сибирь - Тихий океан;

- № 4 - Магистральный газопровод Якутия - Хабаровск - Владивосток.

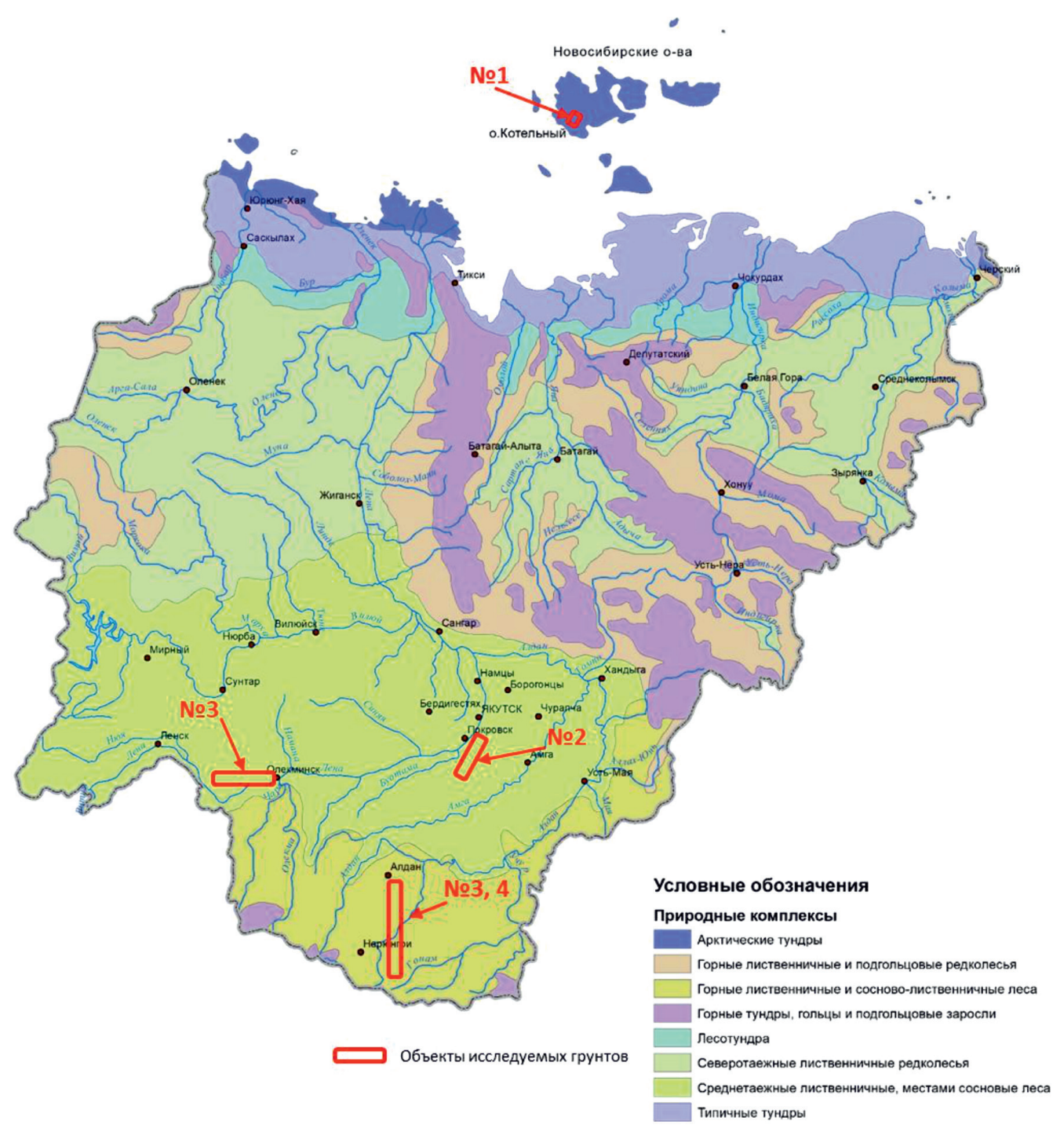

Рис. 1. Места отбора проб грунта на схематичной карте Республики Саха (Якутия) 
В табл. 1 приведены результаты определения гранулометрического состава исследованных грунтов ситовым и ареометрическим анализом [4-6].

Грунты классифицируются от слабольдистых до сильнольдистых. Криогенное стро- ение образцов предварительно изучалось на макроуровне. Фрагменты некоторых из них показаны на рис. 2. Грунты по классу «шлировые» имеют слоистый и сетчатый тип криогенной текстуры, а песчаные грунты - массивную [7, 8].

Гранулометрический состав грунтов

Таблица 1

\begin{tabular}{|c|c|c|c|c|c|c|c|c|}
\hline \multirow[b]{2}{*}{$\begin{array}{c}\text { № } \\
\Pi / \Pi\end{array}$} & \multicolumn{7}{|c|}{ Содержание частиц разного размера в мм,\% } & \multirow[b]{2}{*}{ Наименование грунта } \\
\hline & $\begin{array}{l}n \\
\hat{o} \\
\hat{0} \\
i\end{array}$ & 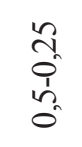 & $\begin{array}{l}\overline{0} \\
\text { 1े } \\
\text { ñ } \\
0\end{array}$ & $\begin{array}{l}n \\
0 \\
i \\
i \\
0 \\
0\end{array}$ & $\begin{array}{l}\tilde{0} \\
0 \\
1 \\
0 \\
0 \\
0\end{array}$ & $\begin{array}{l}\text { ठ̊ } \\
8 \\
0 \\
1 \\
0 \\
0 \\
0\end{array}$ & 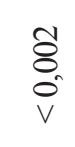 & \\
\hline 1 & 2 & 3 & 4 & 5 & 6 & 7 & 8 & 9 \\
\hline 1 & 9,7 & 58,0 & 21,0 & 11,3 & - & - & - & Песок средней крупности \\
\hline 2 & 6,7 & 33,5 & 45,4 & 14,4 & - & - & - & Песок мелкий \\
\hline 3 & 1,5 & 9,8 & 24,7 & 21,8 & 20,6 & 15,7 & 5,9 & Супесь песчанистая \\
\hline 4 & - & 2,6 & 16,7 & 19,8 & 31,0 & 16,3 & 13,6 & Супесь пылеватая \\
\hline 5 & 1,0 & 7,6 & 13,9 & 25,6 & 28,6 & 14,2 & 9,1 & Суглинок лёгкий песчанистый \\
\hline 6 & - & 4,5 & 8,9 & 21,3 & 38,9 & 17,6 & 8,8 & Суглинок лёгкий пылеватый \\
\hline
\end{tabular}

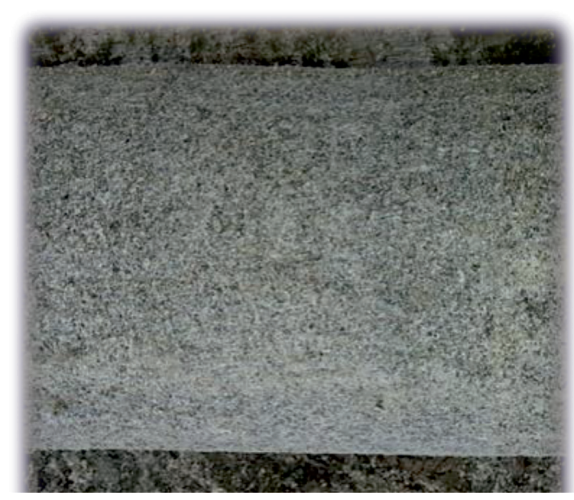

a)

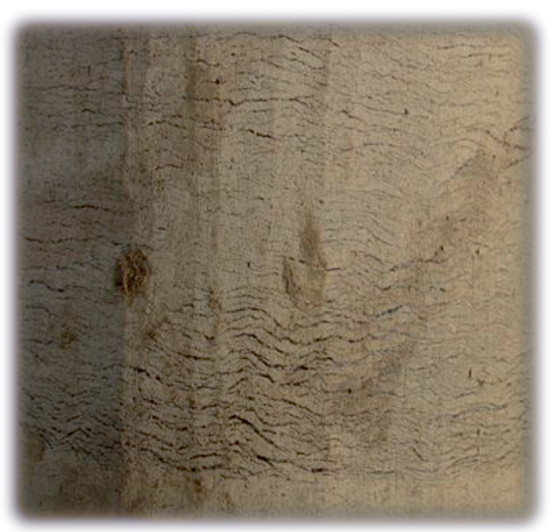

в)

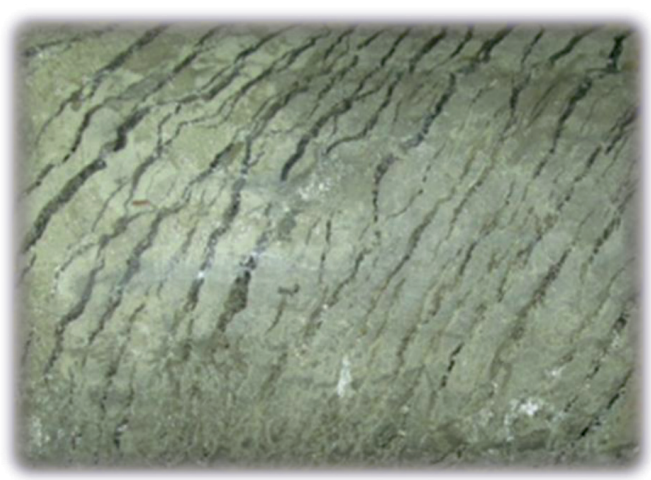

б)

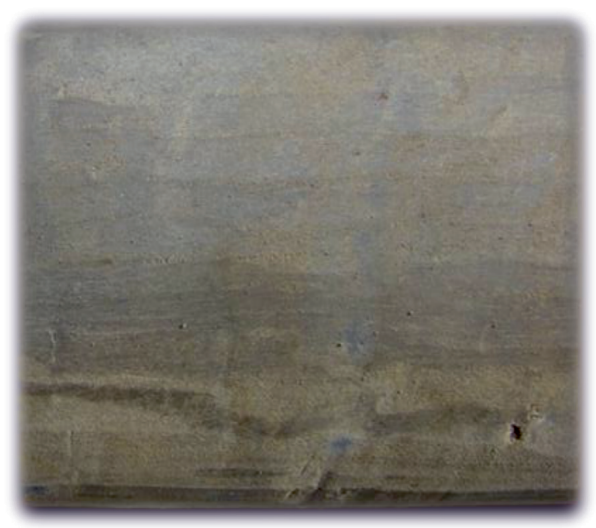

2)

Рис. 2. Некоторые фрагменты криогенных текстур песчаных (а) и глинистых $(б, 6,2)$ мёрзлых грунтов 
Деформационные характеристики оттаивающих грунтов определялись по стандартной методике компрессионного сжатия на измерительно-вычислительном комплексе «АСИС» [9], разработанном научно-производственным предприятием «ГЕОТЕК». Образцы мёрзлого грунта для испытания вырезались из монолита по форме рабочего кольца при отрицательной температуре. Рабочее кольцо с образцом грунта помещалось в одометр и устанавливалось в устройство компрессионного сжатия [10], находящегося в холодильной камере, и выдерживалось перед испытанием при температуре грунта в массиве в течение 12 ч.

\section{Результаты исследования и их обсуждение}

Результаты определений физических и деформационных характеристик 293 об- разцов естественного сложения приведены в табл. 2.

В табл. 2 приведены в числителе дробей минимальные значения, а в знаменателе максимальные значения физических и деформационных характеристик грунтов.

В диапазоне неполного насыщения пор водой $(13,2-24,5 \%)$ коэффициенты оттаивания и сжимаемости песка естественного сложения мелкой и средней крупности, как и коэффициенты искусственных образцов песка, не изменяются (рис. 3). По величине эти коэффициенты практически совпадают.

Зависимости деформационных коэффициентов от пористости грунта так же, как и зависимости образцов искусственного изготовления, выражаются линейной функцией практически с одинаковыми параметрами (рис. 4 и 5).

Таблица 2

Физические и деформационные характеристики исследованных грунтов

\begin{tabular}{|c|c|c|c|c|c|c|}
\hline $\begin{array}{l}\text { № } \\
\text { П/П } \\
\end{array}$ & $\begin{array}{c}№ \\
\text { объекта } \\
\end{array}$ & $W_{t o t}, \%$ & $n, \%$ & $A_{t h}$, д.е. & $m, \mathrm{M \Pi a}^{-1}$ & Наименование грунта \\
\hline 1 & \multirow{2}{*}{1} & $32,0 / 78,6$ & $50,74 / 70,57$ & $0,111 / 0,163$ & $0,062 / 0,086$ & Супесь пылеватая \\
\hline 2 & & $30,0 / 75,0$ & $47,73 / 70,11$ & $0,134 / 0,199$ & $0,069 / 0,105$ & Суглинок лёгкий пылеватый \\
\hline 3 & \multirow{2}{*}{2} & $20,9 / 42,1$ & $40,74 / 57,41$ & $0,089 / 0,147$ & $0,047 / 0,065$ & Супесь пылеватая \\
\hline 4 & & $28,1 / 73,0$ & $47,60 / 69,74$ & $0,119 / 0,201$ & $0,067 / 0,104$ & Суглинок лёгкий пылеватый \\
\hline 5 & \multirow{6}{*}{3} & $13,2 / 23,7$ & $39,1 / 39,85$ & $0,0147 / 0,0160$ & $0,0198 / 0,0221$ & Песок мелкий \\
\hline 6 & & $14,4 / 24,5$ & $39,85 / 40,6$ & $0,0146 / 0,0163$ & $0,0196 / 0,0223$ & Песок средней крупности \\
\hline 7 & & $19,0 / 69,8$ & $38,52 / 68,89$ & $0,096 / 0,164$ & $0,044 / 0,076$ & Супесь песчанистая \\
\hline 8 & & $23,2 / 72,5$ & $43,17 / 69,63$ & $0,120 / 0,189$ & $0,064 / 0,098$ & Суглинок лёгкий песчанистый \\
\hline 9 & & $18,0 / 42,5$ & $37,41 / 57,41$ & $0,085 / 0,128$ & $0,041 / 0,069$ & Супесь пылеватая \\
\hline 10 & & $22,0 / 46,3$ & $42,07 / 59,78$ & $0,124 / 0,184$ & $0,063 / 0,089$ & Суглинок лёгкий пылеватый \\
\hline 11 & \multirow[b]{2}{*}{4} & $20,2 / 41,8$ & $39,63 / 57,04$ & $0,086 / 0,137$ & $0,047 / 0,063$ & Супесь песчанистая \\
\hline 12 & & $22,2 / 46,2$ & $42,07 / 59,78$ & $0,124 / 0,184$ & $0,063 / 0,089$ & Суглинок лёгкий пылеватый \\
\hline
\end{tabular}

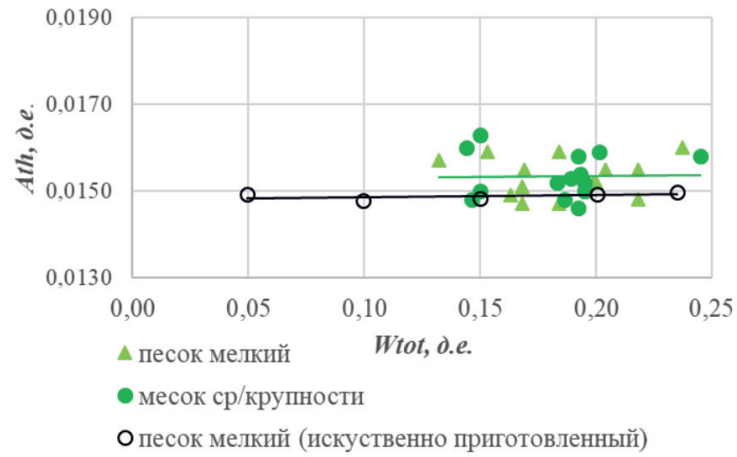

a)

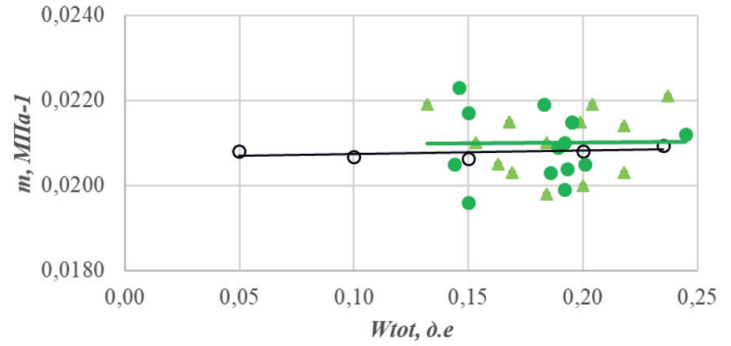

Опесок мелкий (искутсвенно приготовленный) $\triangle$ песок мелкий - песок ср/крупности

б)

Рис. 3. Зависимость коэффициентов оттаивания (а) и сжимаемости (б) песка мелкой и средней крупности и искусственно приготовленного песка мелкого от суммарной влажности 


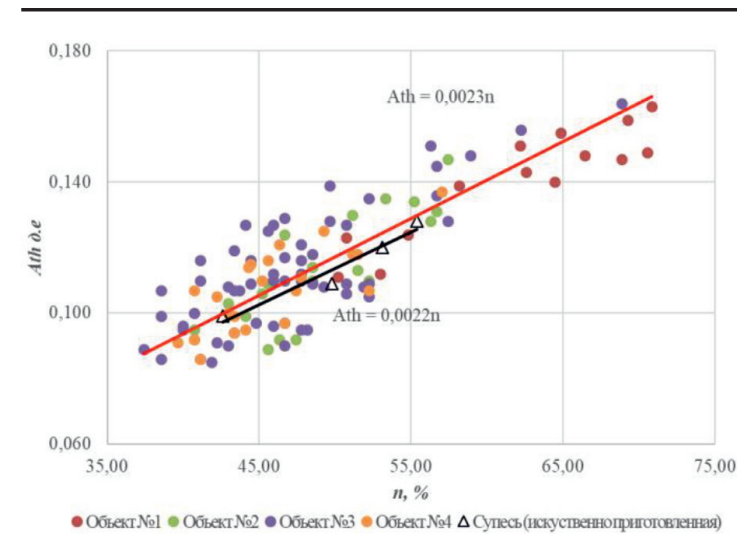

a)

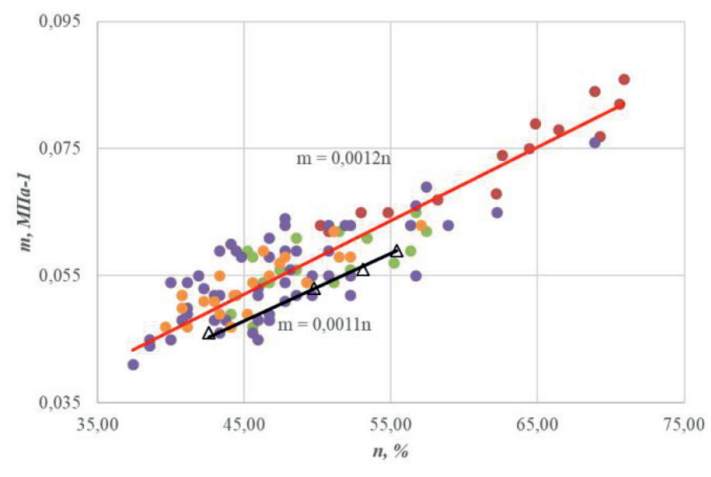

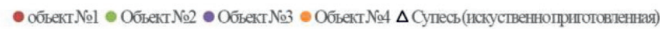

б)

Рис. 4. Зависимость коэффициентов оттаивания (а) и сжимаемости (б) супеси пьлеватой и песчанистой и искусственно приготовленной супеси пылеватой от пористости

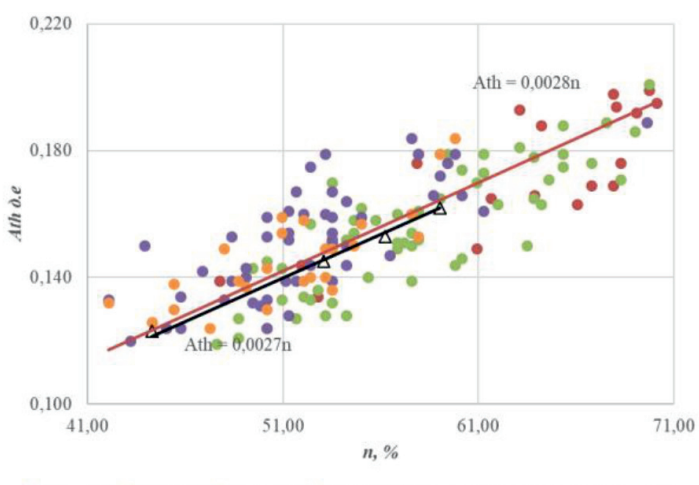

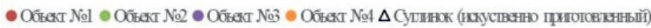

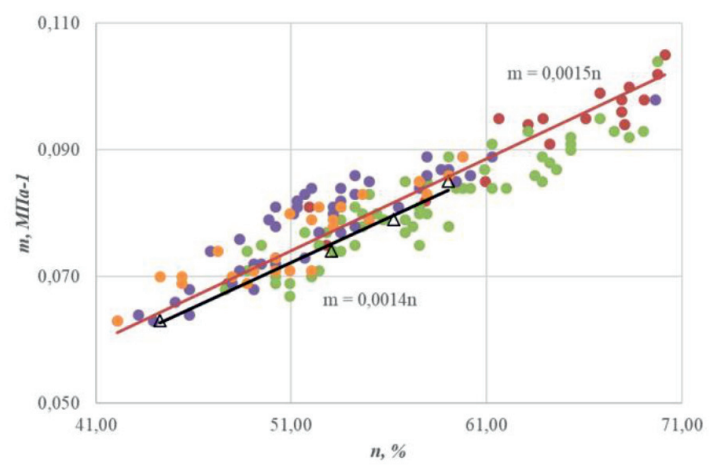

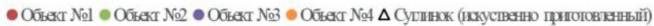

б)

Рис. 5. Зависимость коэффищиентов оттаивания (а) и сжсимаемости (б) суглинка лёгкого песчанистого и лёгкого пьлеватого и искусственно приготовленного суглинка лёгкого пылеватого от пористости

Таблица 3

Результаты статистической обработки деформационных характеристик грунтов

\begin{tabular}{|c|c|c|c|c|}
\hline \multirow{2}{*}{$\begin{array}{c}\text { № } \\
\text { п/п }\end{array}$} & $\begin{array}{c}\text { Наименование } \\
\text { грунта }\end{array}$ & \multirow{2}{*}{ Характеристики } & \multicolumn{2}{|c|}{ Корреляция, д.е. } \\
\cline { 4 - 5 } & & $A_{\text {th }}$ & $m$ \\
\hline 1 & Супесь & \multirow{2}{*}{$n$} & 0,847 & 0,888 \\
\hline 2 & Суглинок & & 0,803 & 0,918 \\
\hline
\end{tabular}

Коэффициенты оттаивания и сжимаемости естественных грунтов ненарушенного сложения выражаются линейными уравнениями:

1) для супесей пылеватых и песчанистых

$$
\mathrm{A}_{\text {th }}=0,0023 * \mathrm{n} \text { и } \mathrm{m}=0,0012 * \mathrm{n} \text {; }
$$

2) для суглинков пылеватых и песчанистых

$$
\mathrm{A}_{\mathrm{th}}=0,0028^{*} \text { п и } \mathrm{m}=0,0015^{*} \mathrm{n} .
$$

В табл. 3 приведены результаты корреляционного анализа полученных значений коэффициентов оттаивания и сжимаемости для двух типов исследованных грунтов.

Таким образом, испытания на компрессионное сжатие естественных и искусственных образцов показали, что деформационные характеристики их при оттаивании выражаются одними и теми же зависимостями от физических характеристик, при- 
чём постоянные в этих зависимостях имеют практически одинаковые величины. Это открывает возможность изучать осадки мёрзлых грунтов при оттаивании на искусственно приготовленных образцах с заданными физическими характеристиками.

\section{Заключение}

Испытаниями в лабораторных условиях получено большое количество значений деформационных характеристик мёрзлых грунтов при оттаивании, образцы которых были отобраны с различных строительных площадок на обширной территории Якутии. Эти данные могут быть использованы для составления базы данных. Установлены зависимости их от физических характеристик грунтов. В качестве паспорта деформационных характеристик мёрзлых грунтов при оттаивании предлагается использовать зависимость их от пористости. Коэффициенты оттаивания и сжимаемости естественных грунтов ненарушенного сложения и образцов искусственного изготовления выражаются одинаковой зависимостью от их физических характеристик. Следовательно, осадки мёрзлых грунтов при оттаивании можно изучать на искусственно приготовленных образцах с заданными значениями физических характеристик.

\section{Список литературы / References}

1. Хрусталёв Л.Н. Основы геотехники в криолитозоне: учебник. М.: ИНФРА-М, 2019. 543 с.

Khrustalev L.N. Fundamentals of Geotechnics in Permafrost: textbook. M.: INFRA, 2019. 543 p. (in Russian).
2. Котов П.И. Обобщение деформационных характеристик оттаивающих грунтов // Основания, фундаменты и механика грунтов. 2013. № 3. С. 23-26.

Kotov P.I. Codification of deformation characteristics of thawing soils. Soil Mechanics and Foundation Engineering. 2013. Vol. 50. № 3. P. 123-127. DOI: 10.1007/s11204-013-9222-z.

3. Вахрин И.С., Кузьмин Г.П. Деформационные характеристики искусственно приготовленных образцов мёрзлых грунтов при оттаивании // Успехи современного естествознания. 2020. № 7. С. 70-76. DOI: 10.17513/use.37434.

Vakhrin I.S., Kuzmin G.P. Thaw deformation characteristics of artificially prepared frozen soil samples // Advances in current natural sciences. 2020. № 7. P. 70-76 (in Russian).

4. ГОСТ 5180-2015. Грунты. Методы лабораторного определения физических характеристик. М.: Стандартинформ, 2016. $23 \mathrm{c}$.

5. ГОСТ 25100-2011. Грунты. Классификация. М.: Межгосударственный стандарт, 2013. 63 с.

6. Трофимов В.Т., Вознесенский Е.А., Королёв В.А. Инженерная геология России. Т. 1. Грунты России: монография / Под ред. В.Т. Трофимова, Е.А. Вознесенского, В.А. Королёва. М.: КДУ, 2011. 672 с.

Trofimov V.T., Voznesensky E.A., Korolev V.A. Engineering Geology of Russia. Volume 1. Soils of Russia: Monograph / Pod red. V.T. Trofimova, Ye.A. Voznesenskogo, V.A. Koroleva. M.: KDU, 2011. 672 p. (in Russian).

7. Ершов Э.Д. Лабораторные методы исследования мёрзлых пород. М.: Изд. МГУ, 1985. $350 \mathrm{c.}$

Ershov E.D. Laboratory Methods for the Study of Frozen Rocks. M.: Izd. MGU, 1985. 350 p. (in Russia).

8. Шестернёв Д.М. Физика, химия и механика мёрзлых грунтов: учеб. пособие. Чита: Изд. Поиск, 2012. 332 с.

Shesternev D.M. Physics, Chemistry and Mechanics of Frozen Soils: a textbook. Chita: Izd. Poisk, 2012. 332 p. (in Russian).

9. Болдырев Г.Г. Методы определения механических свойств грунтов с комментариями к ГОСТ 12248-2010: монография. 2-е изд., доп. и испр. М.: ООО Прондо, 2014. $812 \mathrm{c}$

Boldyrev G.G. Methods for Determining the Mechanical Properties of Soils with Comments to GOST 12248-2010. 2nd ed., updated. M.: OOO Prondo, 2014. 812 p. (in Russian).

10. ГОСТ 12248-2010. Грунты. Методы лабораторного определения характеристик прочности и деформируемости. M.: МНTКC, 2011. $162 \mathrm{c}$ 